\title{
Compilation of Alternative Building Components and Common Distresses Found Through Building Condition Assessment
}

\author{
Vishrantkumar Zambre ${ }^{1}$, Milind Darade ${ }^{2}$ \\ ${ }^{1}$ Dr. D. Y. Patil School of Engineering \& Technology Pune, Maharashtra, India \\ ${ }^{2}$ Professor, Dr. D. Y. Patil School of Engineering \& Technology Pune, Maharashtra, India
}

\begin{abstract}
Buildings being constructed for residential or offices by government or commercial constructions are basically to fulfill demand of shelter due to high increase in the population, change in economic levels, obsolesce of the old buildings and so on. It is important to see here that for any reason if buildings are constructed they do not replace the old ones. Which impose a great responsibility on the shoulders of maintenance engineers to maintain the facility/building to acceptable living conditions? Specific maintenance measures can effectively preserve the value of a building for along time. The planning of maintenance measures requires knowledge regarding the service life of the building components as well as the required maintenance intervals. In many cases, planners refer to the main building components. Compilation of building components is first step towards managing the facility by understanding and knowing the available alternatives their suitability with respect to the designed specifications and selection of appropriate component from the alternatives to be used for new construction. The variety of available alternatives is very high as new products are coming in the market regularly, the only problem faced is its unknown behavior and one has to rely on the manufactures specifications. There are various factors which causes building distress like lack of maintenance, extreme loading condition, faulty design and construction of foundation, poor quality of construction etc which affect on building safety.
\end{abstract}

Keywords: Maintainability, Building condition assessment, Methodology, Factors causing building distress, Main steps of bca.

\section{Introduction}

In order to select an appropriate component this study is undertaken for compilation of alternative building components through regional survey of existing structures from current year back to twenty years, so that the components availability and its performance can guide in selection of appropriate component. Performance of the component over its life span can be of great help in maintenance of the facility/component and to budget the maintenance requirement funds whenever required. Building condition assessment has been used in this study for compiling building components and to report common distresses are to be answered by the planner of construction equipment. Building condition assessment has been used in this study for compiling building components and to report common distresses found in each component over a period of time. This will help understand the maintenance needs of the component. Aim of the work is to compile and find alternative building components and occurrence of common distresses in the buildings through building condition assessment. Scope of this work has been limited to buildings constructed and maintained by government and civil engineering components only have been taken for the study, as for the Mechanical, HVAC and Electrical components maintenance is carried out by the installer or maintenance.

\section{Objective of Project}

1) To study the systems included in buildings

2) To collect data of constructed facilities by government
3)Scrutinize the constructed facilities to enable proper data collection

4)Perform Condition assessment.

\section{Methodology}

a) Selection of buildings

b) Scrutiny of buildings by applying criteria

- Construction year (Last 25 years/ 1985 onwards)

- Type of structure (RCC, Residential building)

c) Preparation of checklist

i. First visit (checklist)

- Blank checklist for compiling components

ii. Second visit for condition assessment (checklist)

- Detailed checklist for condition assessment using following tools.

iii. Tools to be used

a. Visual Inspection(3)

b. Photographs- For Validation

c. Measurements-Damage area Measurement e.g

Cracks- measure cracked area and calculate percentage

damage

$\%$ damage $=$ Cracked area $/$ total area $\mathrm{x} 100$

$=(3 \mathrm{X} 2) /(10 \mathrm{X} 8) \times 100$

$=7.5 \%$

iv. Facility Condition Index (FCI) $=$ Cost of assessed deficiency / Replacement value(3)

v. Interviews: maintenance staff(4)

vi. Layout Drawings-Reference for alteration if any

vii. Report generation 


\section{International Journal of Science and Research (IJSR) \\ ISSN (Online): 2319-7064 \\ Index Copernicus Value (2013): 6.14 | Impact Factor (2014): 5.611}

\section{Data Collection \& Value Stream Collection}

Because the data collected in the inspection process is in form of measurements of the severity of the defects in components, some analysis is required to translate these measurement into a condition value. Once the condition of a component is calculated, that value can be used to calculate the condition at any level in the condition aggregation.

The inspection data is analyzed based on the type of evolution method that is direct- condition rating. An index is calculated for the whole facility, the Facility Condition Index (FCI). The FCI is considered as slandered too, which is used by architects, engineers, and facility planners to compare the condition of facilities and determine whether it is more economical to fully modernize an existing facility or replace it. The FCI is calculated as follows

Facility Condition Index $=$ Cost of assessed deficiency $/$ Replacement value

The cost to assessed deficiencies equals the estimated total costs to repair all life cycle, maintenance, and design deficiencies.

Replacement value is the cost to replace an existing structure with a new structure of the same size at a same location, which can be calculated as follows

Replacement Value $=$ Gross square footage of existing building* Estimated cost (per square foot) of new structure FCIs between 0 percent and 5 percent are considered "good", between 5 percent and 10 percent are considered "fair", and over 10 percent are considered "poor".

Evaluating the condition of building components using a distress survey requires full knowledge of the deficiencies possible in each component. To accurately detect these distresses and measure their severity, a systematic approach to field inspection is important. The aim of the inspection process is to obtain the data required in order to measure and/ or calculate performance or to evaluate the condition of structure that is calculating a numeric value that reflects a specific condition of structure.

Inspection should be performed consistently, accurately, and objectively as possible. To standardize the process, many researchers have developed checklists and deficiency lists for inspection. These lists can be in either paper or electronic format. On other hand some researchers try to automate the inspection process using robots, images, satellite technology, automated devices, smart sensors. Many programs and techniques developed in literature can be categorized in to four main groups:

a) Visual inspection

b) Photographic and optical method

c) Non-destructive evaluation methods

d) Smart sensors

Among the various techniques and technologies that can be used for the condition assessment of facilities, only visual inspection suits the nature of building assets. Visual
Inspections are defined as organized and planned visual examinations conducted by technically proficient personnel. The results of these inspection is a report that depicts the deficiencies or problems for the building components and system of the facility. The report is then used for budgeting and planning.

Visual inspection is not easy, expensive and time consuming process. Site inspection must record the condition of every component in the facility.

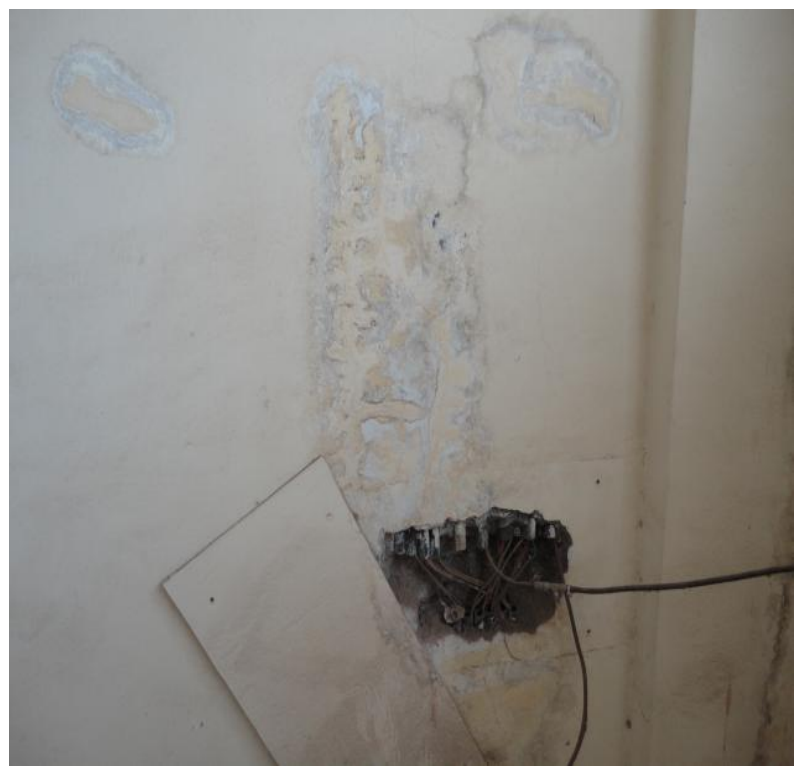

Distress Found in Switch Board

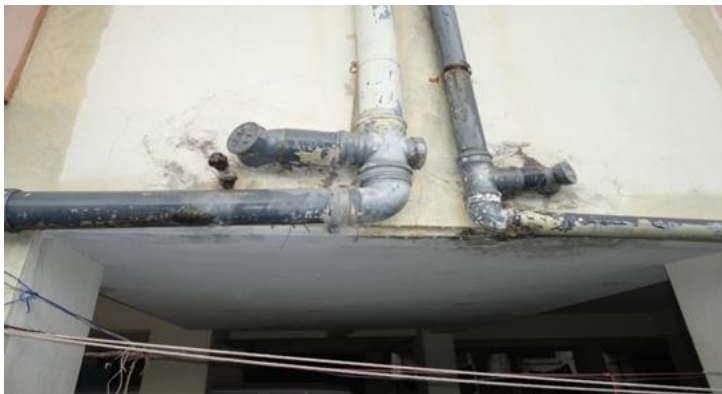

Distress Found in Sanitary System

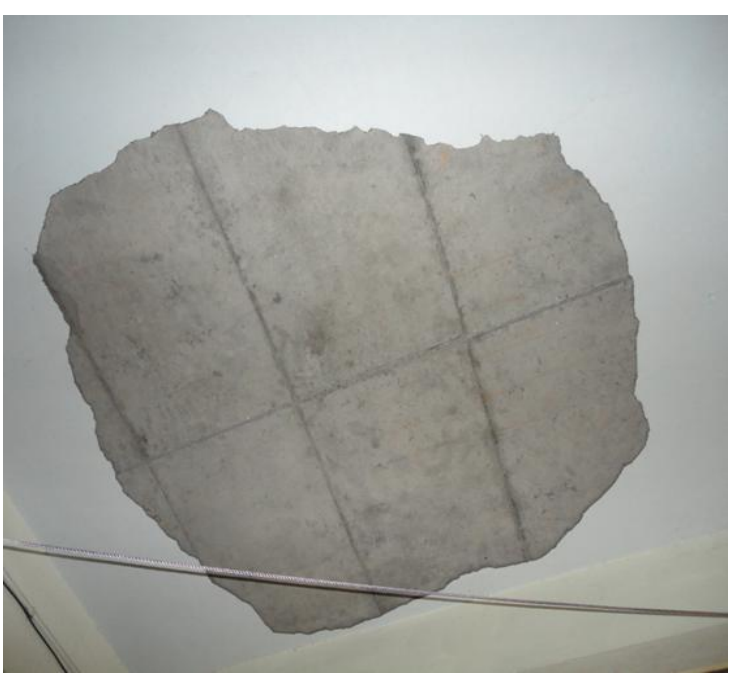

Distress Found in Roof 


\section{International Journal of Science and Research (IJSR) \\ ISSN (Online): 2319-7064}

Index Copernicus Value (2013): 6.14 | Impact Factor (2014): 5.611

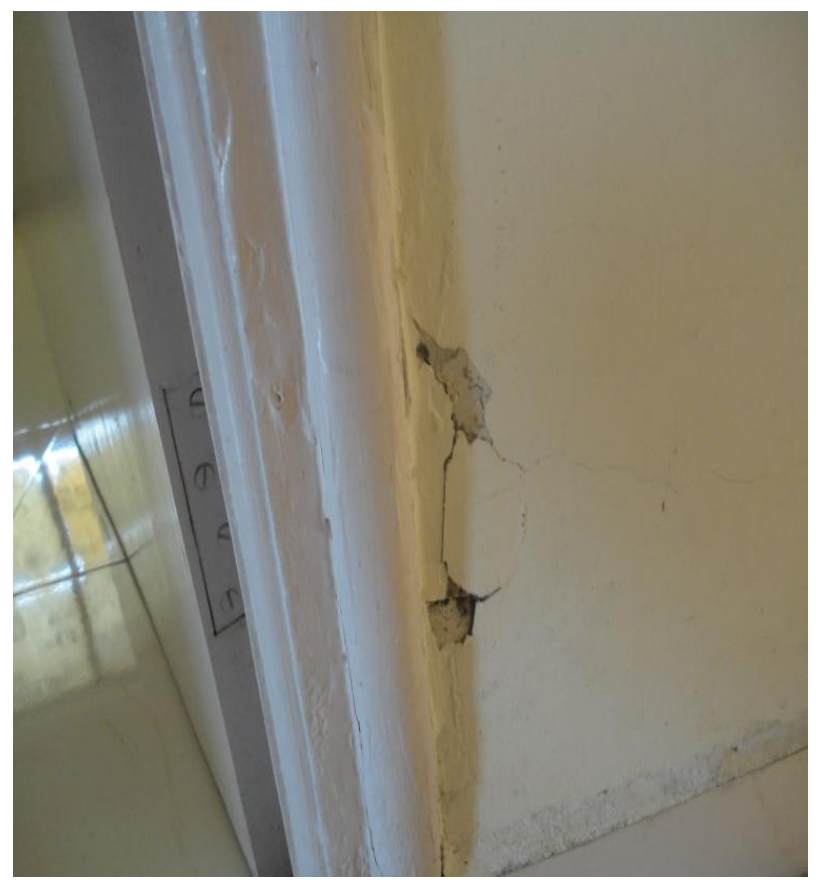

Distress Found in Wall

\section{Conclusion}

Maintenance and repair play a crucial role in the life of your building, and successful maintenance and repair depends on solid performance of other aspects of building management: budgeting, committees, participation, rent collection and communication.

During your building's enrollment in the TIL program, your tenant association needs to establish effective maintenance and repair policies, gather essential information about your building's condition, develop and monitor compliance with the repair plan, prioritize and budget for maintenance and repairs, oversee ongoing maintenance and repair work in the building, and, finally, make sure that the super is doing a satisfactory job. This is obviously a great deal of work, but it will pay great benefits once you make the conversion to being a co-op. Then the tenants will be well prepared to maintain the building in accordance with the standards required by the law - and more important in a condition that makes all of its residents pleased and proud to be living there.

Effective performance of maintenance and repair tasks will give your building's residents a sense of pride and of allegiance to your tenant association. As the physical condition of the building improves, tenants see clear evidence that TIL really works. Their confidence in the program and in themselves grows, and they can take satisfaction that their hard work is paying off. A welldesigned and constructed building will have a relatively maintenance free material. In this case, qualified and experienced civil and structural engineers are essentially needed. Their involvement in building construction has a great deal of responsibility.

In most cases, the problem derives from the design and management phase. To ensure the construction product of the desired quality and to tackle the problem of poor building quality, it is suggested:

a) Increasing protection for owners or building buyers by extending the defect liability period to a certain period.

b) Residents should be allowed to manage their property as soon as they occupy the development. c. A requirement of insurance scheme.

c) The authorities should study the common defects and hold dialogues with property managers who deal with these problems, developers, architects and engineers, so that the problems are not repeated.

\section{References}

[1] $\mathrm{Mr}$.B. B. N. Umeadi Dr K. G. Jones Sustainable Buildings Research Group "From Condition to Performance Assessment of Built Components.

[2] C. C. Roberts, Jr., Ph.D., P.E, Evaluating Cracks in Buildings, http://www.croberts.com

[3] Causes, Evaluation and repair of cracks, ACI 224.IR, American

[4] Concrete Institute, Farmington Hills, MI

[5] Coburn, A.W. (1989), "Seismic vulnerability and risk reduction strategies for housing in Eastern Turkey", Dissertation for Ph.D. Univ. of Cambridge, pp1-212.

[6] "D.R.Uzarski and M.N.Grussing "Building condition Assessment Metrics: Best Practices"

[7] Earthquake engineering Research Institute (1996),"Postearthquake investigation field guide, Learning from earthquakes", Earthquake Engineering Research Institute, Publication No.96-1, pp1-144.

[8] Ferris State university, August 2006“ Facility Condition Assessment Final Report"

[9] Gol-UNDP Disaster, Risk Management Program me, National Disaster Management Division Ministry of Home Affairs, Government Of India, New Delhi, June 2007 " Conditional Assessment of Building for Repair And Upgrading".

[10] G. Reinforced Concrete Structure, MUST, Ulaanbaatar; 2006.

[11] Grunthal G. (1998), "European Macroseismic Scale 1998”, Cahiers du Centre Europeen de Geodynamique et de Seismologie, 15 , pp1-99.

[12] Harvey Kaiser, 2009 "Facilities Condition Assessment" APPSA

[13] Hasegawa K., S. Midorikawa S., and M. Matsuoka (1998), "Seismic risk mapping of wooden house in large area using the grid- square statistics", J. Struct. Constr. Eng., 505, pp53-59 (in Japanese with English abstract).

[14] Koyama M. and Y. Ohta (1999), “A rapid earthquake damage data collection questionnaire system based on local people Cooperation", The 10th Earthquake Engineering Symposium, 3, pp3497-3502 (in Japanese with English abstract).

[15] Moriya K. (1985), "Summary of the 1985 Mexico earthquakes", Shigakusha, pp1-64.

[16] Muramatu I. (1966), "Expectation of Maximum of Earthquake Motion within 50 years throughout Japan", Science Report of Gifu University, 3, pp470-481.

[17]P. Dickinson, N. Thornton, Cracks Caused By Foundation Movement, BRE, ISBN: 978-1-86081-097-8 
[18] R. Park, W. L. Gamble, Reinforced Concrete Slabs, John Wiley \& Sons, Inc. 2000; 2000.

[19] U mass Amherst, 1May 2007 "Building Condition Report", Vice Chancellor for Administration \& Finance.2004 